\title{
Influenza A(H1N1)2009 pandemic Chronology of the events in Belgium
}

by

\author{
Litzroth $A^{1}$, Gutiérrez $I^{1,2}$, Hammadi $S^{1}$
}

\section{Keywords}

Belgium, chronology, epidemiology, influenza A virus H1N1 subtype, pandemic

\section{Introduction}

Mid-April 2009, two cases of a novel Influenza A(H1N1) virus were identified by the Centers for Disease Control and Prevention (CDC)(1). On 26 April, the Government of Mexico also reported 18 laboratory confirmed cases of this virus (2). On 29 April, the World Health Organization (WHO) announced pandemic phase 5 , characterised by human-to-human spread of the virus in at least two countries in one WHO region (3). By this time the virus had also been detected in Austria, Canada, Germany, Israel, New Zealand, Spain and the United Kingdom (4).

The Belgian National Reference Centre for Influenza (NIC) of the Scientific Institute of Public Health (WIV-ISP) confirmed its first case on 12 May 2009 (5). The WHO announced pandemic phase 6 , characterised by community level outbreaks in at least two countries in different WHO regions, on 11 June 2009 (6).

We describe here the chronology of the different events related to the Influenza A(H1N1)2009 pandemic in Belgium from the end of April 2009 until 31 December 2009.

\section{Different phases in Belgium}

Spring 2009: preparedness, first cases and containment phase

On 21 April 2009 the first confirmed cases of influenza A(H1N1)2009 infection were officially reported by the CDC (7). Four days later, the WHO declared the outbreak of this new virus a 'Public Health Emergency of International Concern' (PHEIC) under the International Health Regulations. This declaration obliged all WHO Member States to adapt their surveillance systems in order to collect and notify information related to this event (8). As a response, the Belgian Interministerial Influenza Coordination Committee disseminated protocols for case

\footnotetext{
1 Scientific Institute of Public Health, Operational Direction Public Health and Surveillance, Brussels, Belgium

2 European Programme for Intervention Epidemiology Training (EPIET), European Centre for Disease Prevention and Control, Stockholm, Sweden

amber.litzroth@wiv-isp.be
} 
finding and case and contact management regarding notification, sampling, prophylaxis, treatment and isolation (5).

At the end of April 2009, Belgium adapted its influenza surveillance system, announcing the start of the containment phase, which aims at preventing the spread of the virus. This adaptation implied on the one hand that clinical and virological surveillance by the network of Sentinel General Practitioners (SGPs) and the Belgian NIC continued after the end of the influenza season. On the other hand it implied the establishment of a system for active surveillance for influenza-like illnesses (ILI), targeting travellers returning from affected areas and their close contacts (5), with emphasis on contact tracing.

During this containment phase, only people meeting the case definitions for possible or suspected cases (5) were laboratory-tested. A list of countries with local transmission and countries with sustained community transmission was updated daily ensuring that the most recent epidemiological criteria were used for case finding (9). Initially, laboratory diagnosis was based on exclusion, but from 3 May the specific real time reverse transcriptase PCR was used in the Belgian NIC.

In Belgium the first case was detected on 12 May 2009. By that time the virus had been found in 14 of the 31 European Union and European Free Trade Association countries with evidence of local transmission in the UK only (10).

At the beginning of July, community transmission was detected in Belgium among participants of a music festival (11). At the same time an outbreak was detected in a language camp. These observations combined with the fact that, during the same week, the SGPS found cases among their patients and with the drastic increase in the number of affected countries led to the decision of the Interministerial Influenza Coordination Committee to move on from the containment phase to the mitigation phase on 13 July 2009.

During the containment phase, 126 cases of Influenza A(H1N1)2009 were detected. Isolation in the hospital was recommended only for the first 25 cases and all confirmed cases and their close contacts were treated with neuraminidase inhibitors (11).

Summer 2009: shifting towards mitigation

The switch to the mitigation phase, which aims at reducing the impact of a pandemic (12), included changes in testing and treatment protocols. Possible cases were not systematically tested anymore and treatment was only advised for patients at risk for complications.

As active case finding was stopped, the surveillance of the virus in Belgium relied on the network of SGPs. This network continued virological and clinical monitoring of influenza and ILI. The surveillance approach was similar to the one for seasonal influenza, with the calculation of an epidemic threshold based on the consultation rate among the SGPS for ILI and on the percentage of swabs sent by the SGPs that tested positive for influenza viruses at the Belgian NIC. 
At the same time systems were developed for a detailed monitoring of the impact of the pandemic on public health and on the health-care system in Belgium. This included systems to monitor admission into hospitals for severe acute respiratory infections (SARI) (13), paediatric surveillance of influenza and monitoring of absenteeism.

The interaction between Influenza $\mathrm{A}(\mathrm{H} 1 \mathrm{~N} 1) 2009$ virus and other respiratory viruses and its impact on mortality were closely monitored by existing systems.

On 30 July, the first Belgian citizen died of the consequences of Influenza A(H1N1)2009 infection.

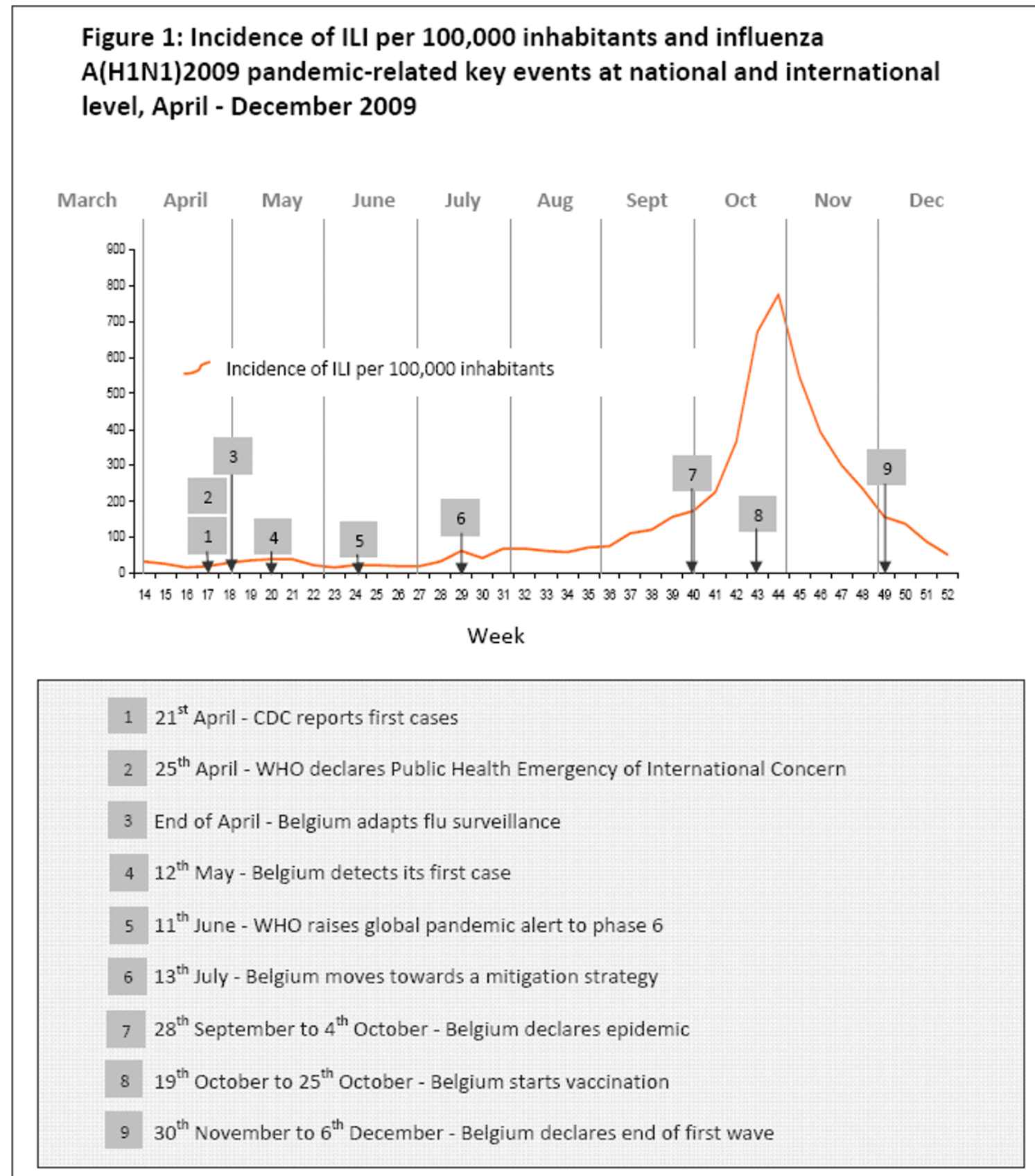


Autumn 2009: epidemic in Belgium

During week 40 (28 September - 4 October) Belgium surpassed the epidemic threshold, with an estimated ILI incidence of 173 per 100,000 inhabitants and with $29 \%$ influenza positive swabs among those sent by the SGPs (14).

Approximately at the same time, Influenza A(H1N1)2009 laboratory diagnosis was decentralised to peripheral laboratories to reduce the workload at the Belgian NIC and to make diagnosis more widely available.

The vaccination campaign against pandemic flu started in week 43 (19 October - 25 October) with the vaccination of health care staff only. The epidemic reached its peak in week 44 (26 October - 1 November) with an estimated ILI incidence of 769 per 100,000 inhabitants and with $73 \%$ influenza positive swabs among those sent by the SGPs (15). In week 45 (2 November - 8 November) the vaccination campaign also began to target the population at risk and the educational staff.

During week 49 (30 November - 6 December) influenza activity in Belgium dropped below the epidemic threshold again, indicating the end of the first wave of the epidemic (16).

By the beginning of winter...

By the end of 2009, 19 deaths in Belgium had officially been attributed to the virus.

A total number of 700,529 on the total Belgian population of $10,666,866$ persons were reported to have been vaccinated against pandemic flu, this is $6.6 \%$. Due to reporting difficulties this figure is very likely to be an underestimation of the real number.

An estimation of the total number of people that have been infected with influenza $\mathrm{A}(\mathrm{H} 1 \mathrm{~N} 1) 2009$ by the end of 2009 ranges between 495,704 and 863,084 (unpublished data).

\section{Conclusion and future perspective}

Since the emergence of the influenza $A(H 1 N 1) 2009$ virus in North America in April 2009, the Belgian NIC has made tremendous efforts in terms of preparedness and response. The virus has been continuously monitored to reduce the impact on public health and health-care systems.

After the end of the first epidemic wave in Belgium and its neighbouring countries, it can be concluded that the overall severity of the pandemic so far has been low. However, the behaviour of pandemic influenza viruses is uncertain. Although since January 2009 only one pandemic flu wave has taken place in Belgium, more waves could follow. Therefore, the WIV-ISP and its collaborating partners will continue the exhaustive monitoring of the virus and its impact. 


\section{References}

1. Novel Swine-Origin Influenza A (H1N1) Virus Investigation Team. Emergence of a Novel Swine-Origin Influenza A (H1N1) Virus in Humans. N Engl J Med 2009; 360(25):2605-15

2. World Health Organization (WHO). Swine flu illness in the United States and Mexico -update 2. [Online]. 2009 Apr 26. [Accessed on 2010 Jan 26]. Available from: http://www.who.int/csr/don/2009_04_26/en/index.html

3. Briand S, Mercer D. Pandemic (H1N1) 2009 situation update on the fifty-ninth session of the WHO Regional Committee for Europe. [Online]. 2009 Sep 14. [Accessed on 2010 Jan 26]. Available from: http://www.euro.who.int/document/RC59/rc59_pres_h1n1_mercer-brand_eng.pdf

4. World Health Organization (WHO). Influenza A(H1N1) - update 5. [Online]. 2009 Apr 29. [Accessed on 2010 Jan 26]. Available from: http://www.who.int/csr/don/2009_04_29/en/index.html

5. Belgian working group on influenza $A(H 1 N 1) v$. Influenza $A(H 1 N 1) v$ virus infections in Belgium, May-June 2009. Euro Surveill 2009; 14(28):pii=19270. Available from: http://www.eurosurveillance.org/ViewArticle.aspx?Articleld=19270

6. World Health Organization (WHO). Current WHO phase of pandemic alert. Current phase of alert in the WHO global influenza preparedness plan. [Online]. 2009. [Accessed on 2010 Jan 26]. Available from: http://www.who.int/csr/disease/avian_influenza/phase/en/

7. Centers for Disease Control and Prevention (CDC). Swine influenza A (H1N1) infection in two children Southern California, March-April 2009. MMWR Morb Mortal Wkly Rep 2009;58(15):400-2

8. World Health Organization (WHO). International Health Regulations (2005) 2nd ed. Geneva: WHO; 2008. Available from: http://whqlibdoc.who.int/publications/2008/9789241580410_eng.pdf

9. European Centre for Disease Prevention and Control (ECDC). ECDC Situation Report. Influenza $\mathrm{A}(\mathrm{H} 1 \mathrm{~N} 1) v$ infection. Update 16 Jun 2009. [Online]. 2009 Jun 16. [Accessed on 2009 Jun 17]. Available from: http://ecdc.europa.eu/en/files/pdf/Health_topics/Situation_Report_090616_1700hrs\%20.pdf

10. European Centre for Disease Prevention and Control (ECDC). ECDC Situation Report. Influenza $\mathrm{A}(\mathrm{H} 1 \mathrm{N1}) \mathrm{v}$ infection. Update 12 May 2009. [Online]. 2009 May 12. [Accessed on 2009 May 13]. Available from: http://ecdc.europa.eu/en/files/pdf/Health_topics/Situation_Report_090514_1700hrs\%20.pdf

11. Gutierrez I, Litzroth A, Hammadi S, Van Oyen H, Gerard C, Robesyn E et al. Community transmission of influenza A (H1N1)v virus at a rock festival in Belgium, 2-5 July 2009. Euro Surveill 2009; 14(31):pii=19294. Available from: http://www.eurosurveillance.org/ViewArticle. aspx?Articleld=19294

12. Nicoll A, Coulombier D. Europe's initial experience with pandemic (H1N1) 2009 - mitigation and delaying policies and practices. Euro Surveill 2009; 14(29):pii=19279. Available from: http://www.eurosurveillance.org/ViewArticle.aspx?Articleld=19279

13. World Health Organization (WHO). Human infection with pandemic (H1N1) 2009 virus: updated interim WHO guidance on global surveillance. [Online]. 2009 Jul 10. [Accessed on 2010 Jan 26]. Available from: http://www.who.int/csr/disease/swineflu/WHO_case_definition_swine_flu_2009_04_29.pdf

14. Belgian National Influenza Centre. Weekly epidemiological report influenza. Period covered: week 40. Brussels: Scientific Institute of Public Health; 2009

15. Belgian National Influenza Centre. Weekly epidemiological report influenza. Period covered: week 44. Brussels: Scientific Institute of Public Health; 2009

16. Belgian National Influenza Centre. Weekly epidemiological report influenza. Period covered: week 49. Brussels: Scientific Institute of Public Health; 2009 